\title{
The Classification Imereti's Landscapes and Its Anthropogenic Transformation
}

\author{
Kubetsia Mzia ${ }^{1, *}$, Shorena Tkemaladze ${ }^{2}$ \\ ${ }^{1}$ Department of Geography, State University of Akaki Tsereteli, Kutaisi, Georgia \\ ${ }^{2}$ National Center for Teacher Professional Development Faculty, State University of Akaki Tsereteli, Kutaisi, Georgia
}

Email address:

Mziakubetsia@atsu.edu.ge (K. Mzia),ShorenaTkemaladze@atsu.edu.ge (S. Tkemaladze)

${ }^{*}$ Corresponding author

\section{To cite this article:}

Kubetsia Mzia, Shorena Tkemaladze. The Classification Imereti's Landscapes and Its Anthropogenic Transformation. Earth Sciences. Vol. 6, No. 6, 2017, pp. 111-116. doi: 10.11648/j.earth.20170606.12

Received: August 4, 2017; Accepted: August 7, 2017; Published: September 29, 2017

\begin{abstract}
The main purpose of this work is to evaluate allocated the landscapes of Imereti and to anthropogenic changes in them. These give chance to determine the current tendencies of different landscapes. The research is based on the field work carried out in different landscapes of Imereti and also on the different scientific sources. This issue is high pressing for Imereti - one of the region of West Georgia. It is connected with a lot of environmental problems such as: activation of natural disasters (flooding, landslides, etc.); increase of soil erosion and degradation; deforestation and over grassing, raising risk of extinction of rare, relic and endemic species; reduce of biodiversity; reduce of agricultural productivity, etc. Thus, in consideration of these problems a special attention should be directed to the consequences of anthropogenic transformations. Imereti is located in a humid subtropical zone and it is distinctive by the various natural-territorial complexes (NTCs). The area of Imereti is $6539.7 \mathrm{~km}^{2}$ and the length of the borders is $389.2 \mathrm{~km}$. Imereti has basically well-defined natural (topographical) borders that grants this regions a physical-geographical distinction and makes it a difficult territorial unit for landscapeecological research. Analysis of the NTCs - every natural landscape unit and the creation of a unified ecological situation in the environment gives us the opportunity to take into account the challenges of the rational use of the buns of beneficiaries that are practical in the regional and local aspects.
\end{abstract}

Keywords: Landscapes, Taxonomic Unit, Imereti

\section{Introduction}

Landscape classification has not only theoretical but practical value as well. It enables sorting similar landscapes and assessing them according to territory planning, resortrecreation management, agricultural management, amelioration and etc.

The issues of landscape classification are considered in many scientific works with different ideas about the essence of landscapes and their classification principles and methods according to numerous parameters $[1,2]$. There are three kinds of landscape conception: general, typological and regional. A landscape simultaneously focuses on regional and typological indicators of the nature. Therefore, it is necessary to take into account these circumstances for landscape classification.
The complex of natural components takes a special place in the landscapes differentiation. Also geological structure has a big importance, which defines the existence of the various forms of terrain. This will result in the morphological, hydro, land and partially vegetation nature of the landscapes. The landscape's dynamics and development is closely linked to the tectonic peculiarities and substructures of the terrain.

Being guided by the modern principles of complex physical-geographical research methodology, we have ensured that large-scale landscapes $(1: 100,000)$ of landscapes in the Imereti region are identified, their cartography and classification are one of the topical problems of physical geography. 
Principles of typological and regional emissions and carting of landscapes in Imereti area demand clear landscape studies in many of the issues, from which we will only pay our attention to landscape classification in our work.

Among the geographers there is a certain disagreement about the typological classification of natural complexes. As a typological unit, a landscape is regularly repeatable in time and space, i.e., one and the same landscape can be met at the same moment of time at different places. Therefore, a landscape includes numerous territories located at long from one another distances (even on different continents). Including them in the same unit is caused by the similarity of the main features of the natural conditions. Unlike the previous concept of landscapes here geographic (territorial) origin is included in its name only in case there are certain common features characteristic of it (geographical object) and making it distinguished from other objects. On the basis of typological conception of landslides two landscape maps have been drawn for the territory of Georgia: the Landscape Map of Georgia, scale 1:600,000 [3] and the Landscape Map of Transcaucasia, scale 1:600,000 [4].

The regional concept considers a landscape in time and space as an unrepeatable unit, i.e., at a moment of time it is met only at a single place and is a concrete territory, which is unique in its genesis, development history and natural conditions. At the one and the same interval of time similar landscapes can be met at different places. However, they are considered only as analogues, object-analogues, analoguelandscapes and not the same landscapes. When speaking about analogues, one emphasizes the most significant, basic characteristics and leaves many other distinguishing features out of attention.

A. Isachenko thinks, the landscape type is the highest taxonomic unit in which the landscapes of the mountain and field are united [5]. According to him the scheme should have such a form: type-class-subclass-unit. The classification of the landscape that is considered as the highest taxonomic unit based on the classical schemes is adopted from ancient times for typological classification in biology and botany, which names the type as the highest level of unit. In contrast, D. Ukleba thinks that if a scheme of taxonomic units for the typological classification of individual components of natural complexes is useful for classification of a natural-territorial complex, it will not be as effective if we deal with a mountain country [4]. According to D. Ukleba offers the scheme of the landscape classification: landscape classlandscape type-subtype-unit.

At present great attention is paid to complex-geographical analysis based on unified geographical approach. This first of all comprises the study of spatial-temporal features of the interrelations of humans and the nature, which depicts characteristics of the nature, population, industry and social sphere and their interrelations. Landscape studies also should be based on the same approaches. This work is based on complex-geographical analysis.

\section{Methods and Initial Data}

The allocation of typological landscapes and the approach to their classification can be divided into 3 parts on the procedure standpoint: 1. Field observation and data collection, 2. Mapping of landscapes. 3. Evaluation of degree of anthropogenic transformations of landscapes.

In preparation of the map, the main stages of landscape design and carting in the research process included preparatory, field and office work. From time to time, the preparatory and durable period required a significant increase in time. We think this process is somewhat legitimate.

At the initial stage, the river erosion network (river gorges, ravines, rhythms, etc.) was designed by the contours on the above-mentioned maps. The subsequent territories between the rivers were divided into sections with different angles: here we have successfully used two kinds of maps for the terrain 1. The horizontal division of the terrain and 2. the inclination of the terrain.

When allocating the boundaries of landscapes, the contours often coincide with the boundaries of the terrain forms or its separate elements. This peculiarity expresses directly that the terrain is the main factor of heat and humidity distribution. At this stage, we have provided important services for fragmentation and inclination maps. Along with this, we always considered the tarrain's macro, mezzo and micro forms. In the studied area, micro-form was considered as the Plate of Imereti, Plateau-Racha Ridge of Imereti, north slope of Adjara-Imereti ridge. Mezzo forms large river valleys, river watersheds terrain and more. Micro form - karst terrain, boilers and etc. The emphasis was placed on the absolute and relative elevations of terrain during the allocation of landscapes. These features were mostly used for the interpretation of the tallest zone.

During the study of the literary and stock sources of various periods and different authors, we had to deal with some conflicting data and some inconsistencies in the contours of the landscape units, which demanded the correction for the verification of the facts.

\section{Research Object}

One of the most extensive historical-geographical region of Georgia - Imereti is located in West of Georgia. It is located in a humid subtropical zone and it is a distinctive by the various natural-territorial complexes. Naturally, such a location significantly defines the nature, complexity and diversity of the natural conditions of the Imereti region, so it has fallen into a peculiar landscape node where the characteristics of the natural complex are characterized by the landscape mosaic.

The area of Imereti is $6539.7 \mathrm{~km}^{2}$ and the length of the borders is $389.2 \mathrm{~km}$.

Imereti is known for its remarkable location extending from the humid subtropical zone, ending high-mountain zone - $2850 \mathrm{~m}$ high up with alpine meadows. It has basically welldefined natural (orographical) borders that grants this 
historical-geographical province a physical-geographical distinction and makes it a difficult territorial unit for landscape-ecological research.

Imereti borders the Likhi Ridge to the east, River Tskhenistskali to the west, the Great Caucasus to the north and Adjara-Imereti Ridge to the south. The Colchic lowland (wester part of the region) is mostly covered with Colchis forest with oak, beech, chestnut, alder and etc. The mountainous parts of Imereti are mainly beech and deciduous forests.

\section{Main Results}

\subsection{Main Landscapes and Vegetation Cover of Imereti}

Imereti is distinguished by a diversity of landscapes, which is connected with topographic peculiarities, geological features, climatic conditions, floristic and edaphic features, etc. Imereti is characterized by different climatic zones (humid subtropical, temperate-humid, cold-moderate). Vertical zoning is well developed. On a relatively small territory there are a number of landscape types, from lowland bogs to the high mountain sub-alpine and alpine meadows.

Despite strong anthropogenic transformation of lowland and foothill landscapes of Imereti, diverse and unique ones still remain in many places, especially in protected area.

The landscapes of Imereti have a different area. The plain anf hoothill lanscales occupy the largest area of Imereti more than $87 \%$ percent of whole area of Region. (Figure 1). The low-mountain and middle-mountain forest lamndscapes make only $5.2 \%$ of the total area of Imereti. Here, a virgin forests occupy the largest area, mostly in middle-mountain forest landscapes. These landscapes have especial a great conservation importance.

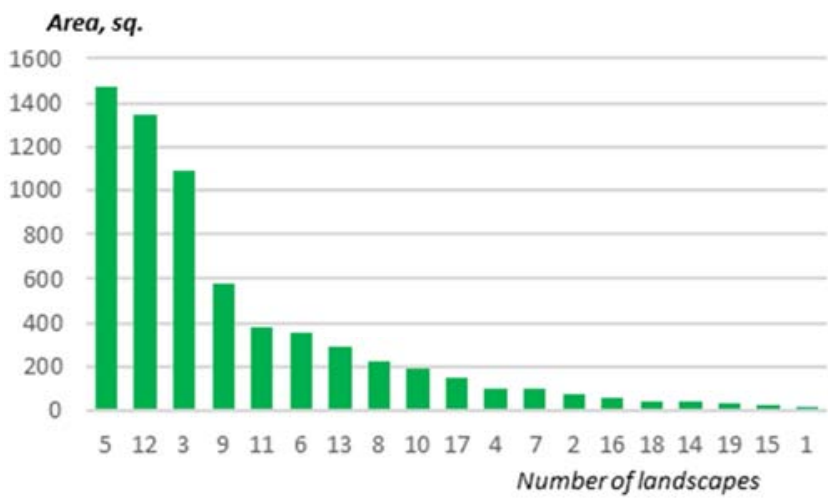

Figure 1. Area of Imereti's landscapes (see legend in the text).

According to Landscape map of Imereti (Figure 2) there are represented by 19 different landscapes.

I. Plain landscapes of humid subtopics

1. Plain and lowland landscapes with wetlands. It is spread in eastern part of Kolkheti Lowland. Hypsometrically, it occupies mostly 0-60 (200) m asl. It has almost totally plain surface promoting bogging. The most dominant vegetation is: Bolboschoenus martimus, Typha angustifolia), $\mathrm{T}$. latifolia, T. angustata, Arundo donax, Cyprus, Phragmites australis, Carex acutiformis, C. vesicaria, C. pseudocyperus, J. effusus, J. inflexus, Sphagnum obesum, S. imbricatum, S. papillosum, etc. The main hazards for the landscape are excess humidity and heavy ground and soil.

2. Floodplain landscapes with forest and meadows, partially with wetlands. It is spread in the floodplain of main rivers (Rioni, Tskhenistjali, Kvirila). The most dominant vegetation is: Salix alba, Populis hybrida, P. gracilis, Alnus barbata, Pterocarya pterocarpa, Ulmus foliacea, U. suberosa, etc.

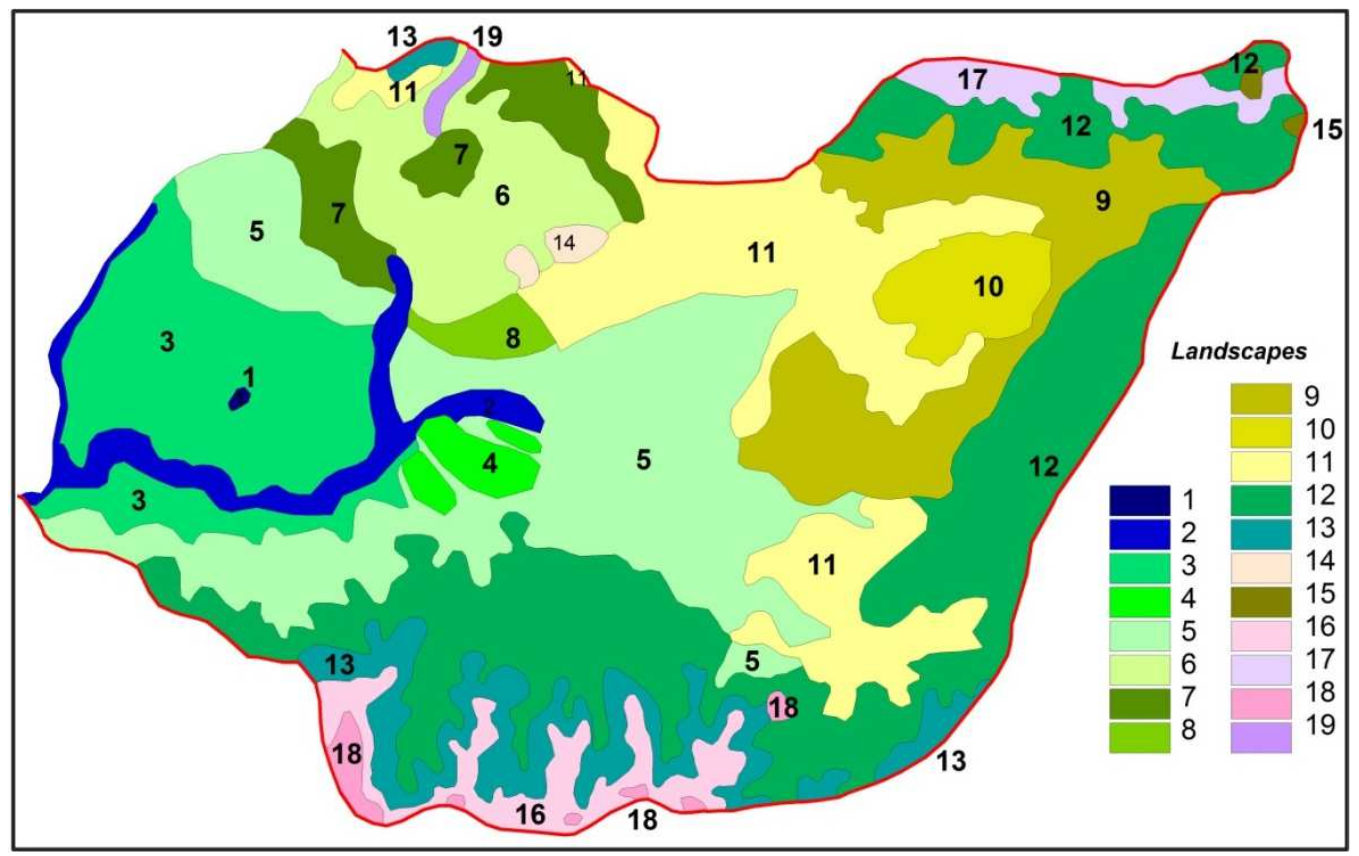

Figure 2. landscapes of Imereti(see legend in the text). 
3. Lowland landscapes with Colchic vegetation (oak forest, somewhere with evergreen understory) on alluvial soils and podzols. In the east, its border reaches the city of Zestaponi, eastern edge of Kolkheti Lowland. In the past the most dominant vegetation was: Alnus barbata, A. glutinosa, Pterocarya pterocarpa, Quercus imeretina, Q. hartwissiana, Carpinus caucasica, Ulmus foliacea, Fraxinus excelsior, etc. During many years was marked by the large anthropogenous pressures on forests of these landscapes. So, the area of forest was decreased. The amount of phytomass varieties between 250-280 t/ha [6]. Most area of the landscape is cultivated with agricultural lands.

4. Lowland landscapes with Colchic vegetation (oak forest), somewhere with zelkova on alluvial soils and podzols. In the past the most dominant vegetation was: Quercus imeretina, Q. hartwissiana, Castanea sativa, Carpinus caucasica, Alnus barbata, Tilia multiflora, elkova carpinifolia, etc. The forests with zelkova are preserved within the boundaries of the protected areas.

II. Plain and Foothill landscapes of humid subtopics

5. Plain and low-foothill landscapes with polydominant forest on rendzina and zheltozem soils. It occupies the central part of Imereti. Hypsometrically, it occupies mostly 150 (200)-350 (450) $\mathrm{m}$ asl. In the historical past, it was covered with strong forest. Under the impact of the anthropogenic factor, the vegetation cover is changed significantly. Dense and impenetrable ash tree forests grow particularly along the river banks and in the cutting areas. In addition to ash trees, there grow oak, hornbeam and other trees. The number of lianas diminishes deep in the forest. This landscape is relatively poor with the vegetation cover. The most dominant vegetation was: Quercus imeretina, Q. hartwissiana, Carpinus caucasica, Alnus barbata, Rhododendron Ponticum, Prúnus laurocérasus, etc. As compared to the previous landscape (\#1), due to a deeper location of the groundwater, the specific weight of hygrophilous plants is reduced. The specific weight of marsh vegetation is reduced, while the specific weight of the forest grass is increased. On the other hand, the areas with oaks, hornbeam and beech are quite vast. Evergreen sub-forest is typical for the given landscape. Out of natural vegetation, Imeretian oak forests and remnants of Kolkhish forest dominate. The amount of phytomass varieties between 75-400 t/ha [6].

6. Foothill landscapes with beech forest on zheltozem.
Hypsometrically, it occupies mostly 200-600 (and more) $\mathrm{m}$ asl in eastern part of Imereti. The most dominant vegetation is: Fagus orientalis, Castanea sativa, etc. Its natural original appearance is strongly changed with the agricultural plots of field covering vast areas. Virgin areas have survived only in protected areas.

7. Foothill landscapes witch oak and beech forest. The most dominant vegetation is: Quercus iberica, Carpinus caucasica, Taxus baccata, Fagus orientalis, Alnus barbata, Castanea sativa, Carpinus orientalis, Tilia caucasica, Fraxinos excelsior, etc.

8. Foothill karst landscapes with Colchic vegetation on rendzina soils. Hypsometrically, it occupies mostly 500-800 $\mathrm{m}$ asl. The most dominant vegetation is: Quercus iberica, Carpinus caucasica, Fagus orientalis and Buxuz baccata in river gorges. The amount of phytomass varieties is more than 250 t/ha [6].

III. Foothill landscapes of humid subtopics

9. Hilly plateau landscapes with oak and hornbeam forest on rendzina soils. The amount of phytomass varieties between 75-400 t/ha [6].

10. Hilly plateau landscapes with oak and beech forest on rendzina and brown soils. The amount of phytomass varieties between 200-400 t/ha [7]. The forests are better survived on the territories adjacent to the mountains. The slopes and gorges of the northern exposition are covered with Kolkhish polydominant forests, while the crests and the slopes of the eastern and southern expositions are covered with hornbeam and oak forests. [8]

IV. Mountainous forest Landscapes with beech and darkconiferous forest.

11. Low-mountain karst landsacpes with oak, hornbeam on rendzina soils. Hypsometrically, it occupies mostly 900 (1000)-1500 m asl. The locations without overgrazing have the young plantings of oak. The amount of phytomass is around $250 \mathrm{t} / \mathrm{ha}$ [6].

12. Middle-mountain landscapes with beech forests mainly with evergreen understory. Hypsometrically, it occupies mostly 1000-1500 (1700) $\mathrm{m}$ asl. The amount of phytomass is more than $300 \mathrm{t} / \mathrm{ha}$ [6].

13. Middle-mountain landscapes with dark-coniferous forests mainly with evergreen understory. Hypsometrically, it occupies mostly 1400-1900 m asl. The most dominant vegetation is: Picea orienatlis and Abies nordmanniana. The amount of phytomass is more than $300 \mathrm{t} / \mathrm{ha}$ [7]. These landscapes ares rich in forests. 
Table 1. Anthropogenic Transformation Degree in Imereti.

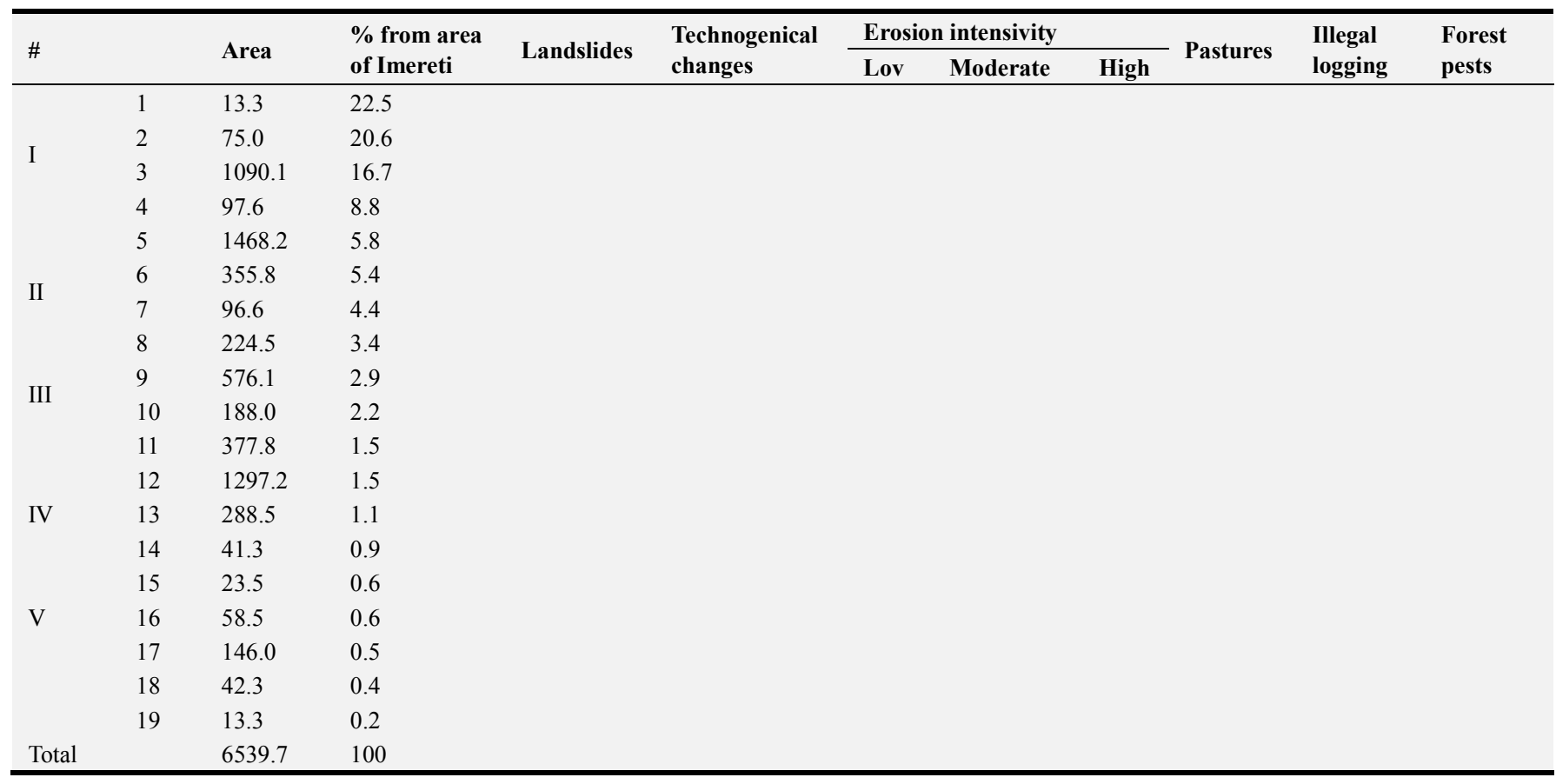

14. Mountain depression with with mixed oak, hornbeam and beech forest on rendzina soils. The amount of phytomass varieties between $75-350 \mathrm{t} / \mathrm{ha}$ [6].

15. Mountain depression partially with wetlands (sphagnum and cane bog).

V. High-mountain sub-alpine and alpine landscapes

16. Sub-alpine meadows with combination of meadows, tall-herb communities, elfin woods and thickets. The most dominant vegetation is: Fagus orientalis, Betula caucasica, Heracleum Augelica, Senecio cineraria, Campanula lactiflora, C. latifolia, etc.

17. Sub-alpine meadows with combination of meadows, elfin woods and thickets on rendzina soils. The most dominant vegetation is: Vaccinium myrtillus, Ribes alpinum, Laurocerasus officinalis, Daphne glomerata, Sorbus graeca, S. velutina, S. colchica, S. subfusca), etc.

18. Alpine meadows with grasslands and rhododendron thickets. The most dominant vegetation is: Betonica grandiflora, Inula orientalis, Geranium ibericum, Alchimilla, Poa alpina, etc.

19. Canons and narrow gorges with rocky plants on primitive soils.

\subsection{Degree of Anthropogenic Transformation}

The most important, that is necessary for evaluating of existing issue for Imereti is determination of following:

1. Population density.

2. Area of agriculture lands.

3. Number of enterprises.

4. Area of transformed landscapes and degree of modification.
Also, an important role play the processes determined both natural and socio-economic processes, because the modern conditions of landscapes are determined by the both processes. The relatively difficult situation is found in some landscapes, where a great number of non-desirable processes are developed. Landslides, soil erosion are widespread in many landscapes (Table 1), inflicting huge damage to the population income, local economy and infrastructure.

The basic factors of evaluation of landscapes changes, it is possible to consider according to following categories:

Practically completely changed landscapes are represented with high population density and a big area of agriculture lands. Here is located the most number of industrial enterprises. Here, almost all relief forms are under the economic impact: floodplains, over-floodplain terraces, plains and elevated areas. These landscapes are: plain and foothill landscapes.

Strongly changed landscapes are represented also with high population density and only $60-70 \%$ of agriculture land of total area of the landscapes. Most of the industrial undertaking of Georgia (63\%) is located in these landscapes, $1 / 5$ of them accounts for particularly polluting enterprises of environment. In every $10 \mathrm{~km}^{2}$ of landscape one industrial undertaking is located. These landscapes occupy a significant part of the plains and foothill landscapes.

Moderately changed landscapes are represented with small density of population and a small area of agriculture lands. In the past, it was covered with strong forest, but anthropogenic pressure changed the situation and the vegetation cover is changed significantly. So, the virgin forest area has significantly declined. These landscapes are: low-mountain forest and high-mountain sub-alpine landscapes with pasture lands. [9]

Slightly changed landscapes are represented with very 
small density of population. The total number of industrial enterprises in these landscapes is insignificant. Most of the middle-mountain forest landscapes are related to them. Also significant part of high mountain sub-alpine and alpine landscapes is related to this category. On the other hand, they are locally fragmented areas because of illegal logging in recent years.

\section{Conclusions}

Using the different sources landscape classification and its anthropogenic transformation were revealed.

As in almost part of Georgia, here is well-expressed vertical zonality of forest. In low altitudes occupy mainly broad-leaved forests (with domination of oak, poplar, oakhornbeam, chestnut). The beech and dark-coniferous forests appear at the middle altitudes (1000-1900 m).

The highest anthropogenic transformation is obvious in plain and foothill landscapes which is strongly changed by agriculture lands. Middle mountain forest landscapes are better preserved, which is caused by complexity of topography. Also high mountain subalpine and alpine landscapes are better preserved than other ones. So, the most forest of Imereti is located in mountainous area, particular in middle-mountain landscapes (with dark coniferous forest), primarily found between altitudes of 1400-1900 m.

A map of landscapes of Imereti has been compiled. This map allows comparing different landscapes for the evaluation of their resource potential.

\section{References}

[1] D. B. Ukleba. Anthropogenic landscapes of Georgia. Tbilisi: Metsniereba, 1983 (In Russian).

[2] N. L. Beruchashvili, D. N. Nikolaishvili. Landscape science. Tbilisi: TSU, 1992 (In Georgian).

[3] M. Saneblidze, D. Ukleba, K. Djakeli. Landscape Map of Georgia. Tbilisi, 1970. scale 1:600,000 (In Georgian).

[4] D. Ukleba. 1970] Landscape Map of Transcaucasia Tbilisi, 1983. scale 1:600,000 (In Russian).

[5] A. G. Isachenko. Landscape science and physicalgeographical zoning. Moscow: Visshaia Shkola, 1991 (In Russian).

[6] D. A. Nikolaishvil. Spatial-Temporal Analysis of Georgia's Landscapes. Tbilisi: State University Publishing House, 2009 (In Georgian).

[7] A. G. Tediashvili A. G. Studying of phytomass as a landscapegeophysical parameter of natural-territorial complexes and its conditions. Tbilisi, 1984 (In Russian).

[8] E. Davitaia, Z. seperteladze. Landscape studies and landscapeecological problems. Tbilisi, Meridiani, 2014 (In Georgian).

[9] Ecoregion Conservation Plan for the Caucasus. 2012. Revised and updated edition. WWF.

[10] M. Kubetsia. Applied geografic ecology. Kutaisi. 2015. (In Georgian). 